\title{
Overview of Problems and Solutions in Fire Protection Engineering of Wind Turbines
}

\author{
SOLOMON UADIALE ${ }^{1}$, ÉVI URBÁN ${ }^{1}$, RICKY CARVEL $^{1}$, DAVID LANGE ${ }^{2}$, and \\ GUILLERMO REIN ${ }^{3}$ \\ ${ }^{1}$ School of Engineering \\ University of Edinburgh, UK \\ ${ }^{2}$ SP Technical Research Institute of Sweden, Sweden \\ ${ }^{3}$ Department of Mechanical Engineering \\ Imperial College London, UK
}

\begin{abstract}
The wind energy industry is one of today's leading industries in the renewable energy sector, providing an affordable and sustainable energy solution. However, the wind industry faces a number of challenges, one of which is fire and that can cast a shadow on its green credentials. The three elements of the fire triangle, fuel (oil and polymers), oxygen (wind) and ignition (electric, mechanical and lighting) are represent and confined to the small and closed compartment of the turbine nacelle. Moreover, once ignition occurs in a turbine, the chances of externally fighting the fire are very slim due to the height of the nacelle and the often remote location of the wind farm. Instances of reports about fires in wind farms are increasing, yet the true extent of the impact of fires on the energy industry on a global scale is impossible to assess. Sources of information are incomplete, biased, or contain non-publically available data. The poor statistical records of wind turbine fires are a main cause of concern and hinder any research effort in this field. This paper aims to summarise the current state of knowledge in this area by presenting a review of the few sources which are available, in order to quantify and understand the fire problem in wind energy. We have found that fire is the second leading cause of catastrophic accidents in wind turbines (after blade failure) and accounts for 10 to $30 \%$ of the reported turbine accidents of any year since 1980 's. In $90 \%$ of the cases, the fire leads to a total loss of the wind turbine, or at least a downtime that results in the accumulation of economic losses. The main causes of fire ignition in wind turbines are (in decreasing order of importance): lighting strike, electrical malfunction, mechanical malfunction, and maintenance. Due to the many flammable materials used in a wind turbine (eg. fiberglass reinforced polymers, foam insulation, cables) and the large oil storage used for lubrication of mechanical components, the fuel load in a turbine nacelle is commonly very large. The paper finishes with an overview of the passive and active protection options and the economics (costs, revenue and insurance) of wind turbines to put in context the value of a loss turbine compared to the cost and options of fire protection. We hope that this paper will encourage the scientific community to pursue a proper understanding of the problem and its scale, allowing the development of the most appropriate fire protection engineering solutions.
\end{abstract}

KEYWORDS: industrial fires, wind, risk assessment, statistics, hazard

\section{THE WIND INDUSTRY}

The world energy context is such that governments and companies are investing in alternative energy sources that do not deplete finite resources and help reduce the possible impact on the climate. In this context, the wind energy industry has presented itself as one of today's leading industries in the renewable energy sector, providing a reliable and sustainable energy solution. Some examples follow. The European Commission (EC) has set a binding target to produce 20\% of European Union's (EU) energy demand from renewable sources by 2020 , and wind energy is expected to produce $12-14 \%$ of EU's power demand to meet the 2020 binding target [1]. Currently, in South Australia, more than 20\% of the energy demand is met by energy produced from wind farms [2-4].

Recent work [6,7] has shown that the growth of the wind energy industry from the mid 90's to 2012 has been large, with a global installed power capacity of $282 \mathrm{GW}$ at the end of 2012 as shown in Fig. 1, representing a cumulative market growth of more than 19\%. Fig. 2 shows that most of the recently installed capacity is (in order) in Asia, Europe and North America. The Global Wind Energy Council's (GWEC) market forecast for the wind energy industry expects a continued growth during the period for 2012-2016.

However, as in most of the energy industries, fire is a concern in the wind industry. The three elements of the fire triangle, fuel (oil and polymers), oxygen (wind) and ignition (electric, mechanical and lighting) are 
represent and confined to the small and closed compartment of the turbine nacelle. Moreover, once ignition occurs in a turbine, the chances of externally fighting the fire are very slim due to the height of the nacelle and the often remote location of the wind farm. Fuel control, detection and automatic suppression remain the only tools for protection.

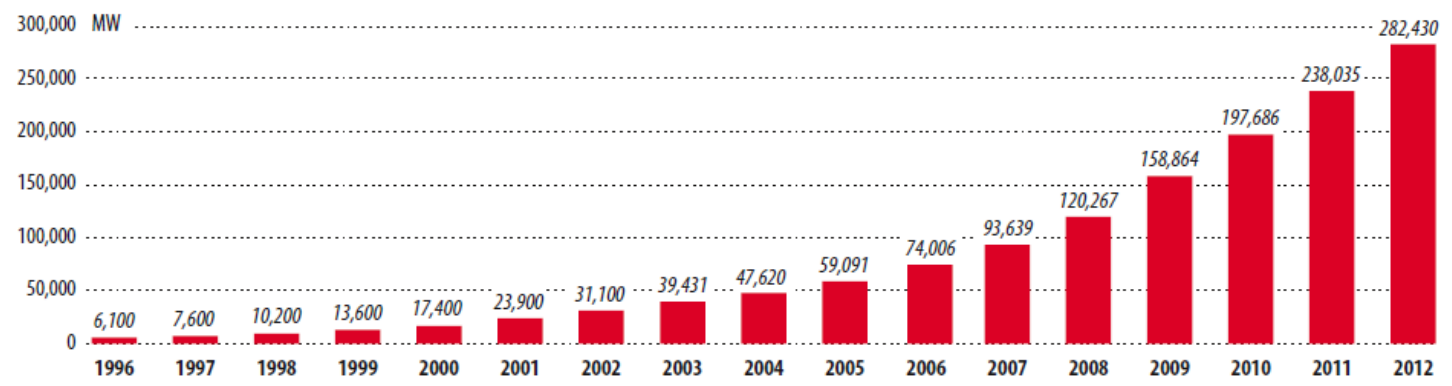

Fig. 1. Global cumulative installed wind capacity 1996-2012 [6]

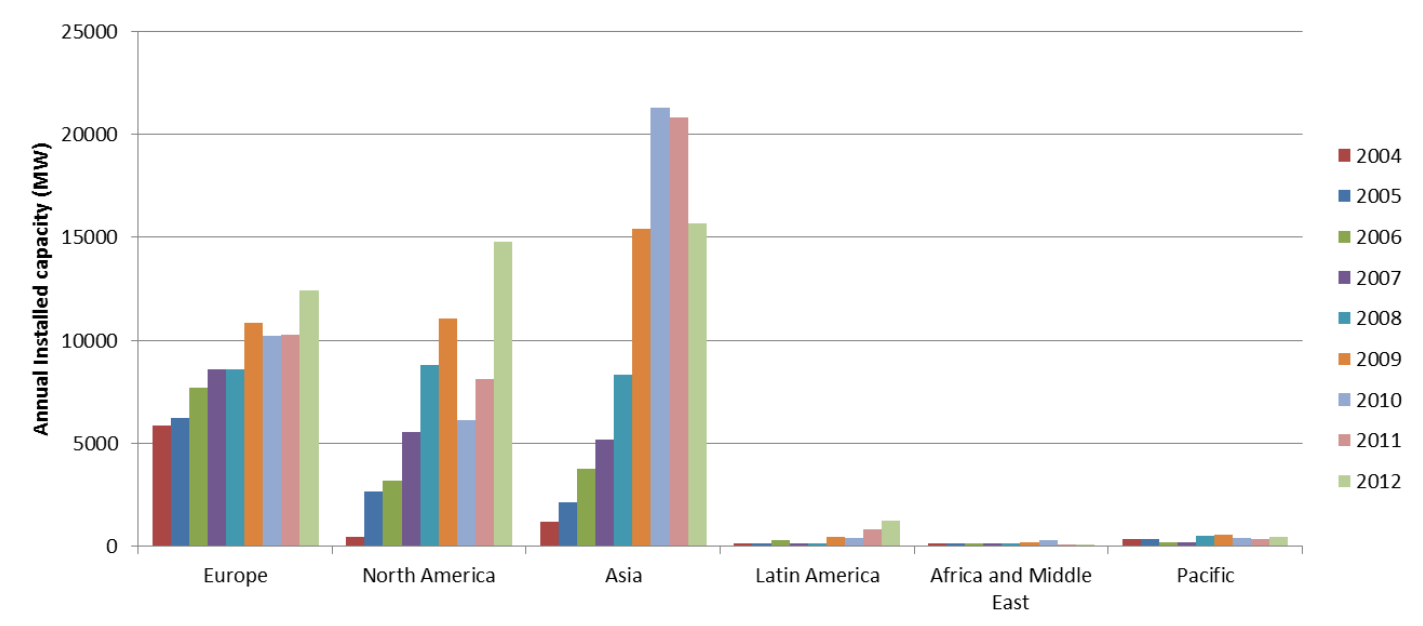

Fig. 2. Annual installed capacity by regions of the world 2004-2012, adapted from [6].

Regional news has reported occasionally about fires in wind farms but the true extent of the problem at a global scale is exceedingly difficult to assess. Most sources of information are incomplete, biased or nondisclosed because of proprietary data. This paper aims at filling this gap and presenting an extensive review of all sources available in order to quantify and understand the fire problem in wind turbines. The hope is that a proper understanding of the problem and its scale will allow for development of the best fire protection engineering solution, as the need of such a solution is indeed vital to the sustainability of wind turbines and to the growth of the wind energy industry.

\section{THE TURBINE FIRE PROBLEM}

The fire problem becomes apparent judging from the accident statistics show in Figure 3 which shows the yearly evolution of the number of wind turbine related accidents, including fire incidents. Fire accounts for a substantial fraction of the accidents of any year, between 10 to $30 \%$. Because the absolute number of fire accidents tends to increase with the number of installed turbines, the expected growth in the installation of wind turbines, also bring the expectation of an increase in the number of turbine fires. However, the ration of fire accidents per turbine installed has decreased significantly since 2002.

The fire problem in wind turbines arises as a result of large amounts of highly flammable materials (hydraulic oil and lubricants, composite materials, insulation, and polymers) contained within the nacelle of the wind turbine and packed in close proximity to potential ignition sources such as overheated mechanical components (hot surfaces) and electrical connections that could fail [8-12]. 
Once a fire is ignited in a wind turbine, the situation rapidly escalates because the high wind favoured by turbine locations enhances the supply of oxygen and, hence, the fire growth. In over $90 \%$ of wind turbine fires reported, a total loss of the wind turbine, or at least, a severe structural failure of the major components (blades, nacelle, mechanical or electrical components) has been reported [8].

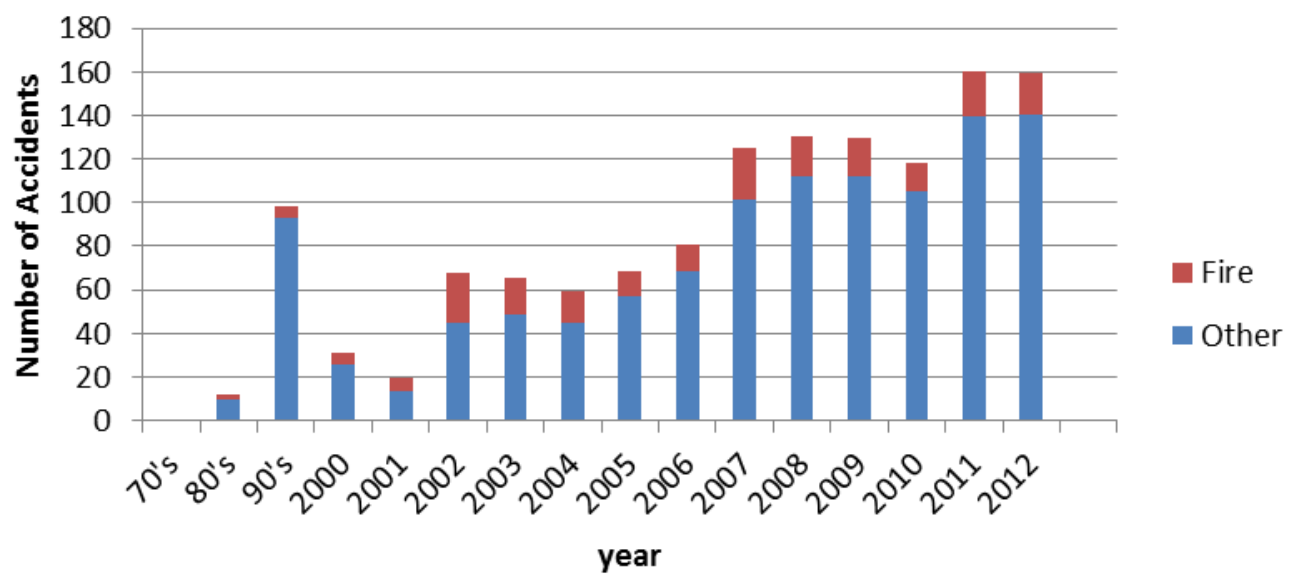

Fig. 3. Accident statistics worldwide, including fire, since 1980's as collected by the UK lobby group Caithness Windfarm Information Forum (CWIF) [8]

Moreover, even in the case of rapid detection, the fire brigade cannot intervene because of the turbine height $[9,10,12]$, and for offshore wind turbines it is impractical to send response teams to fight the fire [9]. Under high wind conditions, burning debris from the turbine may fall on nearby vegetation and start forest fires or cause serious damage to property (see Fig. 4) [10].

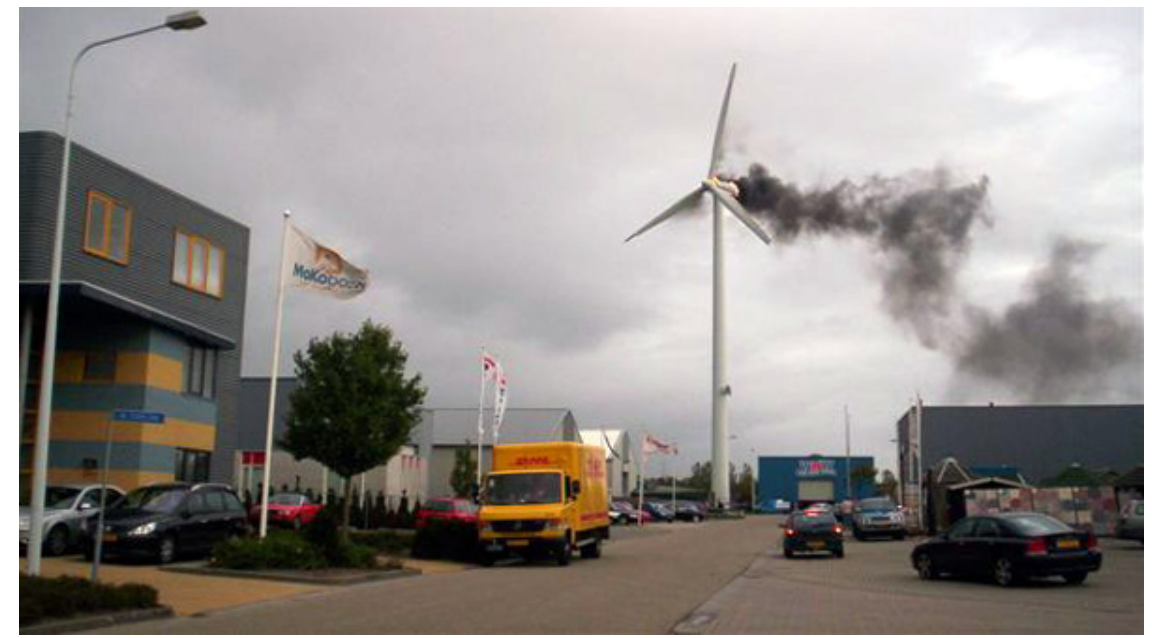

Fig. 4. A burning wind turbine located in an urban area [13].

\section{FIRE STATISTICS}

According to the statistics collected by the Caithness Windfarm Information Forum (CWIF) [8], through press reports and other publicly available documents across the world but mostly in Western countries, there has been a growing trend in accidents since 1970s with an higher rate between 1995 and 2012 (see Figure 3). This recent acceleration is thought to be mainly due to the growing number of installed wind turbines while the protection technology remains the same. The total number of turbine accidents recorded in the period 1995-2012 was 1328. The most common cause of accidents in wind turbines is blade failure with 251 registered instances (19\%). It is closely followed by fire with a total of 200 incidents recorded, which is $15 \%$ of all the reported accidents. This represents on average 11.7 fires per year ( $\sim$ one fire accident per month). None of the fire accidents led to fatalities, but three workers were injured in 2008 and 
another one in 2012 because of turbine fires. The third most common cause, with 130 incidents (9.7\%), is structural failure.

The figure of 11.7 turbine fires per year may not seem a great number compared to the fact that there were $\sim 200,000$ wind turbines worldwide in 2011 [16]. However, due to the excessive financial loss that a fire can cause, especially in a small wind farm, it is an issue that owners and insurers are keen to address. From the statistics gathered, it is worth noting that in over $90 \%$ of the fires that originated in the nacelle of a wind turbine, a total loss or severe structural damage of the wind turbine was experienced. In some cases additional damages to the surroundings were also incurred due to secondary ignitions of nearby property from burning debris.

However, these numbers are believed to be only the tip of the iceberg, as many cases are not made public, and hence go unregistered [8]. This statement is supported by the fact that the British newspaper The Telegraph [14] obtained information from the wind industry reporting that about 1500 wind turbine accidents occurred within the United Kingdom (UK) alone between and 2006 and 2010. This was confirmed independently by Renewable UK. CWIF statistics for the UK in that period documented only 142 accidents, which is just about $9 \%$ of what The Telegraph reported. Thus, we can argue that the publicly available tip of the iceberg represents about $10 \%$ of the total number of fires, and that a rough average estimate is 117 fire accidents per year (ten times the figures reported by CWIF in Figure 3).

Additional concerns on the inconsistency of the data is that all the fire instances found by CWIF occurred in onshore wind farms, and no information was available for offshore farms. However, fires occur in offshore wind farms as well, as $\mathrm{Mr}$ Denis Lefebvr [15], technical director at windfarm operator AEROWATT, confirmed that at least he knows of a number of small fires in the electrical shelters at the bottom of several offshore wind turbines. The poor statistical records of wind turbine fires are a main cause of concern and hinder any research effort in this field.

\section{CASE STUDIES}

The following is a brief description of four selected case studies extracted from the literature (presented in chronological order) for the purpose of illustrating some generalities and the heterogeneity of the fire problem in wind turbines.

\section{Nissan factory, Sunderland, UK, 2005}

The Nissan wind farm project completed in August 2005 was the first wind farm within the car manufacturing Nissan group and the first wind farm in the North East of the UK to be enclosed entirely within an industrial area [27]. The Nissan $€ 2.7$ million wind farm project has six Vestas wind turbines with capacity of 6.6 MW installed at the Nissan car factory in Sunderland. The six wind turbines installed at the wind farm provide about $7.5 \%$ of the Nissan factory's annual electricity requirement [28]. The energy generated from the wind farm will save the Nissan car plant up to $€ 950,000$ annually, and it was estimated that the project would pay for itself in four years [29].

On December $23^{\text {rd }} 2005$, one of the turbines was engulfed in fire and lead to its total loss and the disruption of traffic on the nearby highway A19 due debris hazards as well as the $55 \mathrm{~m}$ wind turbine falling onto the road. Fire-fighters from the Tyne and Wear fire brigade attended the scene but could do nothing to save the turbine due to its height and the burning debris falling to the ground. The fire-fighters manage to avoid secondary ignitions on the ground out of the safe perimeter around the tower.

Repair works were carried out on the turbine the previous day to the accident, as a fault in the turbine had been reported. The turbine caught fire shortly after it was restarted [30]. Upon investigation, it was found that a loose bolt had jammed a rotating mechanism (probably the drive train) which resulted in the overheating of the turbine brakes [31].

\section{Lake Bonney, Tantanoola, Australia, 2006}

The Lake Bonney Wind Farm (also known as Canunda Wind Farm) developed by Infigen Energy is one of Southern Australia's largest wind energy project in terms of generating capacity [23]. The project was developed in three stages and has a total of 112 turbines giving a combined capacity of $278.5 \mathrm{MW}$.

On January $22^{\text {nd }}, 2006$ one of the turbines caught fire during a heat wave. The incident led to the shutdown of the farm, leaving some 63,000 homes without electricity [24]. The Border Watch newspaper reported 
that some 80,000 ha of national park were destroyed by a wildfire ignited by the turbine debris. Dozens of fire-fighters rushed to the scene to contain the fire, backed by the efforts of two water bomber aircrafts [25].

Investigation into the cause of the fire found that the cause was an electrical failure within the turbine nacelle [26]. Additionally, the accident resulted in a downtime with dozens of turbines on the farm shut down. The Vestas turbine which cost about $€ 2.2$ million was completely destroyed, but the total loss incurred by this accident far exceeds the cost of the turbine.

\section{Ardrossan, Ayrshire, UK, 2011}

On 8th December 2011, a wind turbine caught fire during a heavy storm in North Ayshire despite being non-operational. The wind turbine was completely burnt out and burning debris were scattered across a long distances due to the strong wind (see Fig. 5).

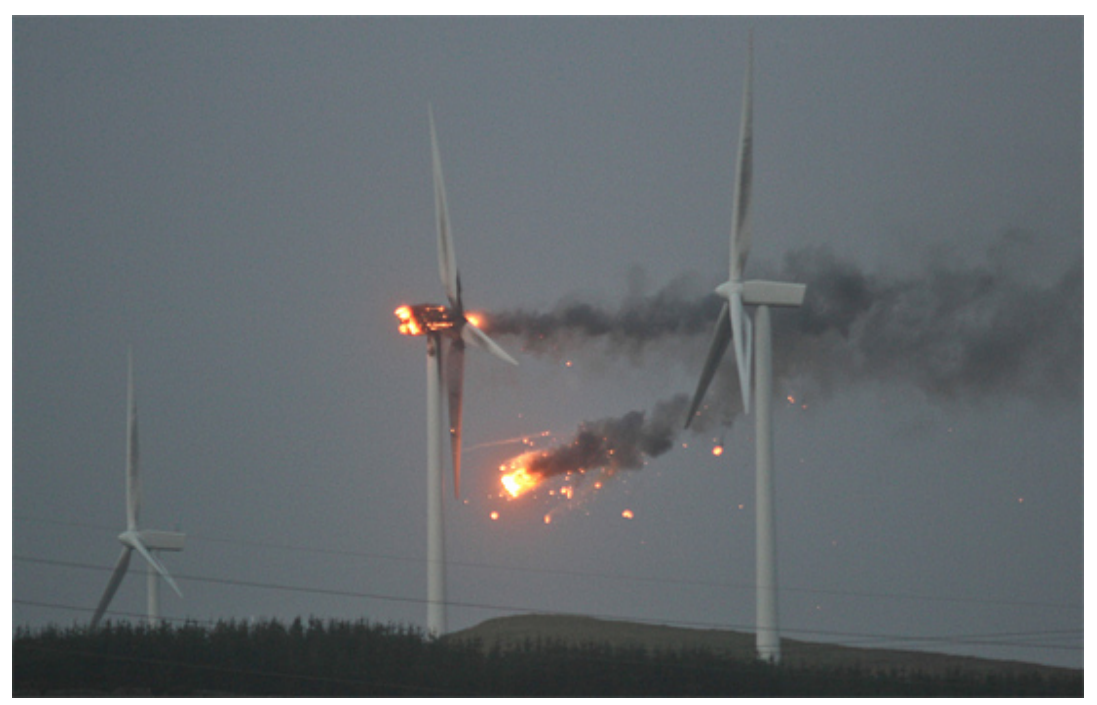

Fig. 5. Wind turbine fire at Ardrossan wind farm [17].

The cause of the fire was said to have been a lightning strike to the turbine. The turbine was completely destroyed. Secondary ignition of nearby vegetation and property was avoided due to timely fire service intervention. The wind farm lost about 1,210 MWh of energy in the weeks after the fire due to downtime.

This fire got a lot of attention and received some strong criticism especially from those who were already against wind energy, one of which was Sir Bernard Ingham, secretary of the Supporters of Nuclear Energy group, who said: "They are no good when the wind doesn't blow and they are no good when the wind does blow" [18].

\section{Groß Eilstorf, Germany, 2012}

The Groß Eilstorf wind farm project in Lower Saxony, Germany began operation in 2011/2012 and has a 51 MW capacity with a total of $17 \mathrm{~V}-112,3 \mathrm{MW}$ wind turbines from the Danish wind turbine manufacturing company Vestas. On March 30, 2012 one of the newly installed wind turbines caught fire (see Fig. 6). The machine house of the turbine and one of the blades burned down. The time to repair the turbine was estimated to be at least a year with a potential loss of $€ 300,000-400,000$. The cause of the fire was identified to be a loose connection in the electrical system in the harmonic filter cabinet which caused an arc flash [19-21].

\section{DESCRIPTION OF TYPICAL FUEL LOADS}

Understanding and quantifying the source of the high fuel loads typically founds inside a wind turbine is an essential step if the fuel control or the design alteration options are desired for fire protection.

The fuel load in a wind turbine nacelle is frequently high, but depends on the type of turbine, and is made of four main components: polymers, insulation, cables and oils. The two main existing types of turbines are the Vertical Axis Wind Turbine (VAWT) and the Horizontal Axis Wind Turbine (HAWT). VAWT are use 
very little so far and most turbines currently installed are HAWT for commercial power generation. The HAWT is further divided into two types; the direct drive HAWT and the gear-driven HAWT. A geardriven HAWT typically houses an even greater fuel load because of the large amount of oil and lubricants stored [10].

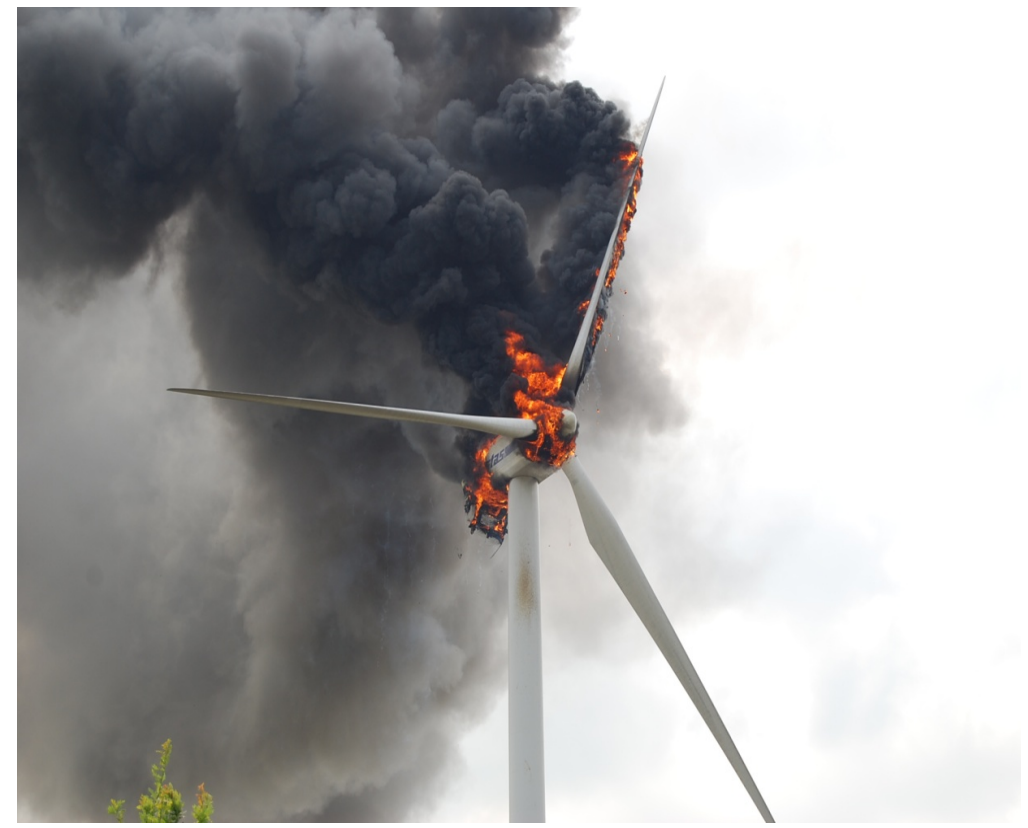

Fig. 6. Wind turbine on fire at the Groß Eilstorf wind farm [22].

Typically, wind turbine nacelles are made from fiberglass reinforced plastic (FRP). This is the main fuel element during flame spread over the nacelle. FRP is flammable and difficult to extinguish due to the epoxy resins used in fusing the fiberglass $[32,33]$. Materials used for internal acoustic insulation of the nacelle, which are often made from foam, are also a major part of the load [9, 10]. These insulation materials are highly flammable as well, and can easily soak up spilled oil, thus giving them an even greater fire potential. Electrical installations and thick long electrical cables spanning from the nacelle to the base of the tower also constitute a great amount of polymers.

Wind turbines located in arid environments are exposed to airborne dust during the hot seasons, which can find its way into the nacelle (especially for turbines without climate control). The dust can easily absorb spilled oil deposits to form a thick combustible mixture (up to several centimetres if clean-up maintenance activities are not regular) [34].

The nacelle can house a huge amount of flammable liquids including gearbox oil, transformer oil, hydraulics fluids and other lubricants. For example, in a single $1.5 \mathrm{MW}$ wind turbine, up to 9001 of lubricating oil including cooling and cleaning fluids can be stored inside the nacelle [11]. The transformer of a sub-megawatt wind turbine located at the base of the tower can easily contain an additional 22001 of transformer oil [11], which means that for a multi-megawatt wind turbine with its transformer located inside the nacelle, the fire load is increased dramatically. The substation transformers where a group of turbines connects to the grid contain over 45,000 1 of oil each [11]. Also, oil-containing waste that has not been disposed creates an additional fuel load.

\section{IGNITION SOURCES}

A number of sources can trigger a fire inside a wind turbine. The most commonly identified ignition sources (in decreasing order of importance) are: lighting strike, electrical equipment malfunction, hot surface ignition, and hot work maintenance ([9-11], [35]). These are reviewed in the following text.

Lightning strikes on wind turbines have been identified as the most common ignition source. Offshore turbines operating in more challenging weather conditions, multi-megawatt onshore turbines with heights exceeding $100 \mathrm{~m}$, and turbines located at high altitudes, all face a high risk of lightning strike which could 
result in fire ignition. The fire risk dramatically increases when an adequate lightning protection system is absent or has not been maintained [9].

Another common ignition source is electrical/electronic equipment failure or malfunction. Overheating/ overloading of electrical/electronic components can lead to failure and subsequently fire. Short circuits, arcs, and inadequate electrical protection are common causes of fire in wind turbines [10]. Electrical/electronic component failures leading to fire are frequent in the power electronics (transformer, switchgear cabinet, and inverter cabinet), power converter, control electronics, SCADA (Supervisory Control and Data Acquisition) and DCS (Distributed Control System) systems. There is also the everpresent threat of fire due to loose or broken electrical connections.

"Malfunction of electrical components, wrong fixing between cables, and also, components that are not properly tested before commission are common reasons for fire in wind turbines. A few cases of arson have also been noted" - [50].

Hot surfaces such as overheated bearings, gearboxes, and mechanical brakes can pose a high fire risk in wind turbines if flammable materials come in contact with them. A wind turbine at the Tir Mostyn \& Foel Goch wind farm in Nantglyn, Denbighshire, Wales, UK caught fire and suffered a total loss due to an overheated gearbox [8].

"In general all components which are producing heat or store flammable liquids are potential fire sources. That means for a wind turbine: generators, azimuth-engines, gear boxes, hydraulic aggregates, control electronics and cooling systems. In my opinion, the most critical components are generators, hydraulic aggregates and engines." - [51]

In emergencies, when aerodynamic brakes fail to stop the turbine at speed close to or above the turbine's cut-out speed, mechanical braking systems are applied, and they can pose a high fire risk as they can overheat (especially if poorly lubricated), reach very high temperatures, and also produce flying sparks which could ignite flammable materials (for braking systems without protective covers) [10], [35]. Overheating of the braking system may result in the breaking off and propelling at reasonable velocity of disc brake fragments, which might come in contact with, and possibly rupture hydraulic hoses within the nacelle, resulting in the expulsion under high pressure of highly flammable hydraulic fluid exposed to hot surfaces, thus resulting in a hot surface spray ignition [36]. Even in the absence of disc brake failure, failure of hydraulic pumps and their connections are not uncommon in wind turbines, so as spillage of gearbox and generator oils. These fluids can easily come in contact with hot surface or sparks generated by mechanical friction or electrical arc, and cause a spray or pool fire.

Maintenance and repair activities involving "hot work" such as flame cutting, welding, soldering, and abrasive cutting can result in a high fire risk especially in a gear driven HAWT. Flammable materials at distances up to $10 \mathrm{~m}$ or more could easily be ignited by sparks from grinding, welding, and cutting activities, and most fires have been reported to occur several hours after completion of hot work inside the nacelle $[10,35]$

\section{WIND TURBINE COSTS}

Wind power is one of the most cost-effective renewable energy technologies in terms of cost per $\mathrm{kWh}$ generated. The total installed costs are dominated by the upfront capital cost which can make $84 \%$. The capital cost for an onshore wind turbine can be split into the categories shown in Fig. 7 [37].

Installed costs for wind power systems vary greatly between countries; the lowest cost countries include Denmark, China and India whereas installation costs are significantly higher in Japan, Austria and Switzerland [37]. The capital cost of offshore wind turbines is approximately twice as much as for onshore wind turbines - this is due to the higher costs of transportation of materials, construction and installation at sea, but also the turbine itself needs extra protection against the marine environment [37]. An estimated cost breakdown for offshore turbine installation - capital investment is $2400-3700 € / \mathrm{kW}(1300-1800 € / \mathrm{kW}$ for onshore wind turbines), of which $30-50 \%$ (65-84\% for onshore wind turbine) is the wind turbine cost.

A wind turbine design cost and scaling model was developed by the National Renewable Energy Laboratory's (NREL) National Wind Technology Center to estimate the cost of wind energy [38]. As examples, the estimated initial costs for erecting an onshore and offshore wind turbine are presented in 
Table 1 and Table 2 respectively. As can be seen, a typical 1.5MW onshore wind turbine would have a total initial cost of approximately $€ 1.1$ million while a $3 \mathrm{MW}$ offshore turbine would cost around $€ 4.9$ million.

The revenue generated from a wind turbine depends on its output capacity, a $1.5 \mathrm{MW}$ wind turbine generates about $€ 580,000$ and a $2-2.2 \mathrm{MW}$ wind turbine generates approximately $€ 0.9-1.1$ million per year in revenue [39]. If the turbine is out of operation due to a fire, this loss of revenue is in addition to the damage costs. The guidelines of VdS (Germany's independent testing institution for fire protection) estimates a loss of $€ 5000$ per week if a 20 -year-old $2 \mathrm{MW}$ wind turbine is out of operation [35]. In case of offshore wind farms, hiring the necessary equipment for repair is also costly. As an example, a fire in an offshore wind turbine caused a damage of $€ 2$ million, out of which the cost of hiring the necessary equipment for repair was approximately $30 \%$ [40]. It is reported that insurance claims are high, ranging between $€ 1-1.2$ million per incident [41].

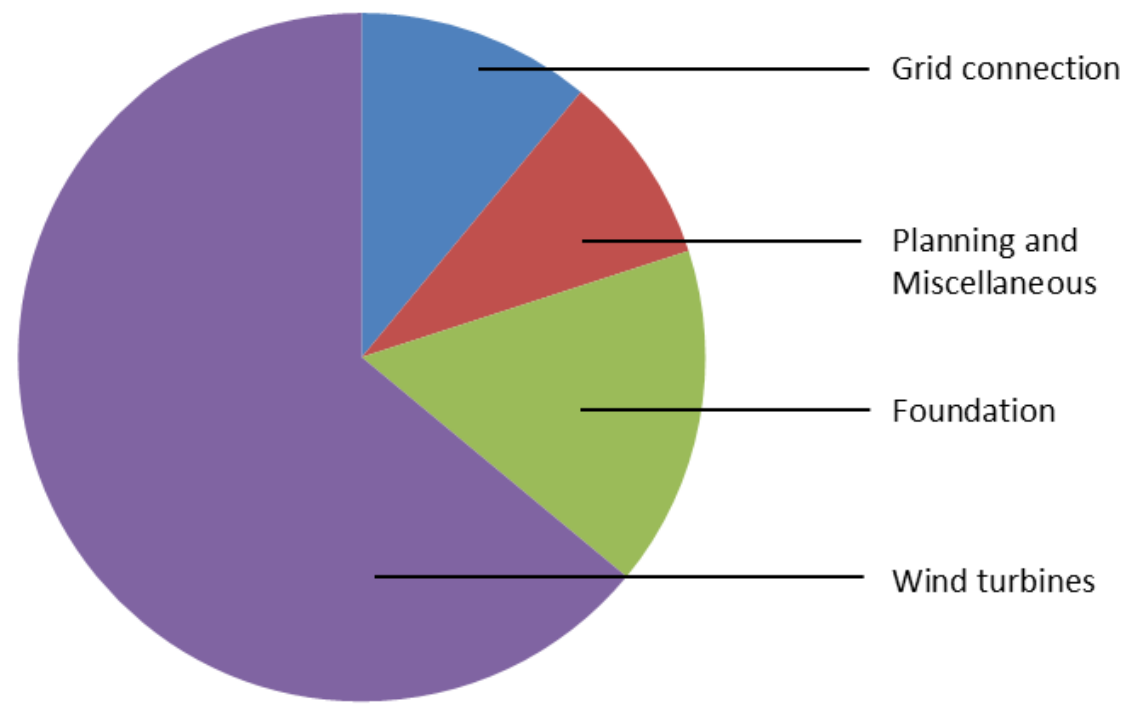

Fig.7. Capital cost breakdown for an onshore wind turbine, adapted from [37]

Table 1. An onshore 1.5MW turbine cost estimate (rotor diameter $70 \mathrm{~m}$, hub height $65 \mathrm{~m}$ ) [38].

\begin{tabular}{|l|r|}
\hline Component & Costs $\mathbf{€ 1 0 0 0}$ \\
\hline Rotor & 175 \\
\hline Drive train, nacelle & 457 \\
\hline Control, safety system, condition monitoring & 26 \\
\hline Tower & 108 \\
\hline Wind turbine cost & 766 \\
\hline Station costs (foundation, transportation, assembly etc.) & 271 \\
\hline Total initial cost & $\mathbf{1 0 3 7}$ \\
\hline
\end{tabular}

Table 2. An offshore 3MW turbine cost estimate (rotor diameter $90 \mathrm{~m}$, hub height $80 \mathrm{~m}$ ) [38].

\begin{tabular}{|l|r|}
\hline Component & Costs $\mathbf{6 1 0 0 0}$ \\
\hline Rotor & 353 \\
\hline Drive train, nacelle & 1054 \\
\hline Control, safety system, condition monitoring & 44 \\
\hline Tower & 307 \\
\hline Marinization & 237 \\
\hline Wind turbine cost & 1994 \\
\hline Station costs (foundation, transportation, installation etc.) & 2463 \\
\hline Offshore warranty premium & 264 \\
\hline Total initial cost & $\mathbf{4 7 2 2}$ \\
\hline
\end{tabular}




\section{FIRE PROTECTION GUIDELINES}

As the wind industry continues to rapidly expand, the need for reliable fire protection systems is of great importance. The VdS guideline on wind turbine fire protection [35], later adopted by the Confederation of Fire Protection Associations in Europe (CFPA-E) [10] in order to establish a common European guideline, highlights the issues of wind turbine fires and puts forward recommendations for wind turbine fire prevention, detection and suppression. The current (2010) edition of the US standard NFPA 850: "Recommended Practice for Fire Protection for Electric Generating Plants and High Voltage Direct Current Converter Stations" has a chapter that deals with the fire safe design of wind turbine generating facilities.

\section{Passive Fire Protection for Wind Turbines}

Passive fire protection in wind turbines can be implemented in several ways, but mainly by targeting the key components that are known to be potential ignition sources, and components that are easily combustible and can enhance flame spread to other components within the turbine nacelle. A good engineering solution would be to redesign the wind turbine and reduce the fire load inside the nacelle (i.e. direct drive). The main passive fire protection options for wind turbines include:

- Installation of a comprehensive lightning protection system [9, 10, 35, 42, 43].

- $\quad$ Use of non-combustible hydraulic and lubricant oil [9, 10,35]

- Installation of a radiant barrier to protect combustible solids (FRP, insulation) in the nacelle [44]

- Avoiding the use of combustible insulating materials in the turbine nacelle where possible, otherwise, flame retardant materials should be applied [9, 10, 35].

- Avoiding carrying out maintenance and repair activities that involves "hot work" inside the turbine nacelle if possible. Such activities should be carried out by cold procedures (sawing, screwing, cold bonding, etc.) $[9,10,35]$.

- Applying condition monitoring systems (CMS) to check the condition of critical systems and carry out regular maintenance checks where necessary $[9,10,35]$.

\section{Active Fire Protection for Wind Turbines}

Active fire protection systems come into play when there is a fire and are comprised of fire detection and alarm systems, smoke management and suppression systems.

In order to detect a fire, the detector has to respond to one of the characteristics of a fire environment: smoke, flame or heat. Detectors can be categorized as smoke, heat, flame or gas combustion detectors. Fig. 8 shows the detector types and the matter or energy conversion phenomena during the fire which they respond to.

Smoke detectors can detect the visible and invisible aerosol particles created by the fire. The unconsumed carbon and carbon-rich particles make up the visible products, while the solid particles smaller than 5 microns, ions and gases form the invisible products. In general, smoke detectors generally respond faster than heat detectors. On the other hand, they are usually more likely to have false alarms, especially in dusty, dirty places and are also influenced by temperature extremes (lower than $0^{\circ} \mathrm{C}$ or higher than $38^{\circ} \mathrm{C}$ ) and high humidity ( $>93 \%)$. [45]. In the case of wind turbines, smoke detectors will also be influenced by the air flow in the nacelle enclosure which may in fact be quite fast under high winds, depending upon the turbine age and type.

Conversely, heat detectors have a great resistance to environmental conditions and are generally less sensitive, which means they have fewer false alarms. They detect clean burning fires, but are unlikely to respond to smouldering fires [46].

Flame detectors respond to the optical radiant energy that is generated by diffusion flame combustion. They are used for specialized applications to detect rapidly spreading fires, but cannot detect smouldering fires [45], [46], [47], [48]. There are two types of flame detectors [45]:

- The ultra-violet detector operates at wavelengths $<400 \mathrm{~nm}$

- $\quad$ The infra-red detector operates at wavelengths $>700 \mathrm{~nm}$ 
Flame detectors cannot detect non-flaming fires, such as smouldering or some electrical fires. They are comparatively costly, and only work with an unobstructed view - water, smoke, ice on lenses and heat sources make them less sensitive. [49]

Finally, gas combustion detectors detect the gaseous products of combustion, mainly carbon-monoxide. They are effective in detecting smouldering and ventilation controlled fires, but do not respond well to flaming and well-ventilated fires. They are usually used in sleeping accommodations and confined spaces [45-47, 49].

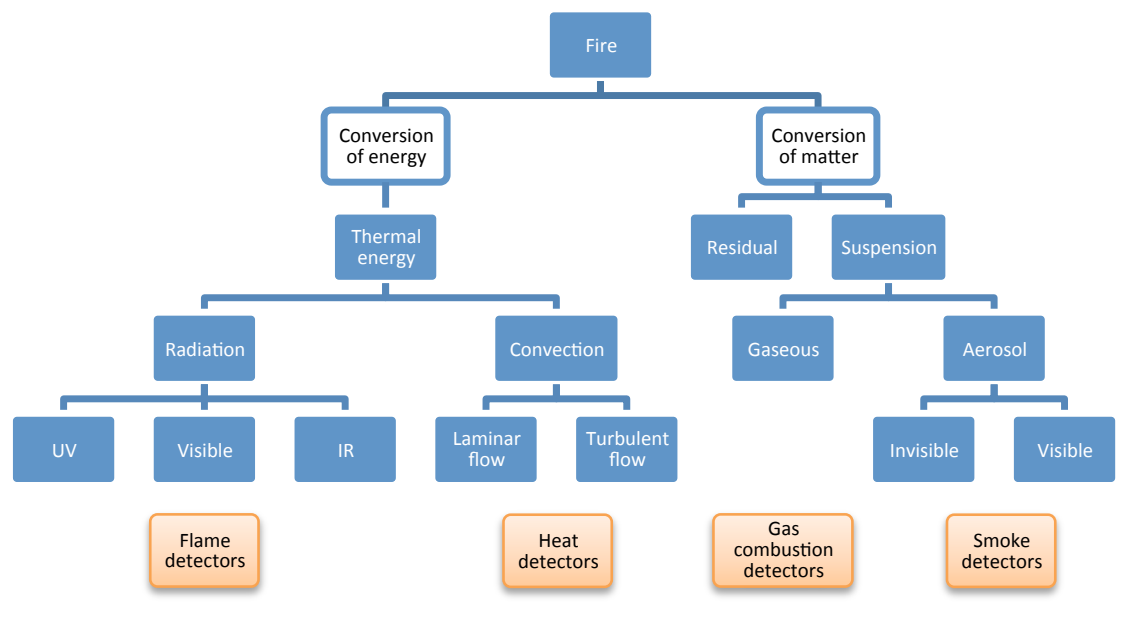

Fig. 8. The working principle of detectors, adapted from [45]

Suppression systems are either meant to extinguish the fire, or control it until the fire service arrives. In case of a wind turbine where the burning nacelle cannot be put out by traditional fire-fighting means, complete extinguishment would be required from the built-in system. In order to extinguish a fire, at least one of the following traditional principles should be applied [45]:

- Isolation of the fuel (physical or chemical isolation)

- Reduction of temperature

- Reduction of the oxidizing agent (oxygen)

- Neutralizing/braking the chain reaction.

Clearly the efficacy of any system which is based on these principles is strongly influenced by the environment in which the hazard is located. For example: space and weight saving considerations in the design of wind turbines limit the potential for water based fire protection systems, whereas the nature of the nacelle structure, with openings around joints for rotating machinery and at the top of the tower mean that effectiveness of any flooding systems will be limited. Fixed protection systems which are focused on extinguishing fires in certain components inside of the nacelle may alleviate some of these issues, however multiple suppression systems would lead to increased cost and complexity of the fire protection system inside of these structures.

While the likelihood of a fire inside of the turbine is relatively small, the cost of any incident is significant. Without a fixed fire-fighting system any fire in a wind turbine is very likely to lead to a total loss. The aim of installing a fire detection and suppression system would be to minimize fire damage, reduce the cost of repair and shorten any downtime while the cause of the fire is investigated and the turbine repaired.

\section{DISCUSSION AND CONCLUSIONS}

This article has highlighted the unique nature of the fire problem faced by the wind energy industry, as well as the paucity of available information about such fires in the public or scientific domains. There are numerous examples of accidents reported in the popular press, all of which highlight the significant impact and ensuing downtime due to fires. These fires result in financial loss, power loss (which is especially 
problematic in remote locations where the wind turbines are a major source for electricity), as well as secondary damage, for example through road closures or ignition of wild fires in rural areas.

There is however very little scientific information available publically from which to evaluate the problem critically, since much of this information is proprietary. What is known and apparent, however, is that because of the nature of wind turbines, fire-fighting is difficult. The nacelles are significantly elevated above ground level, beyond the reach of most fire-fighting appliances. Turbines are often located in remote rural areas, increasing response time. Yet the environment inside of a wind turbine nacelle may lead to increased likelihood of ignition because of the choice or design of the components, and to increased difficulty in detection or suppression since the favoured environment requires high flow of air around the nacelle and through it in the case of some designs. Therefore, where fires do occur there is - in the majority of cases - a $100 \%$ loss of the turbine structure and the only recourse of fire-fighters is often to attempt to limit the spread of the fire to other areas.

The wind energy industry has shown steep growth over recent decades, and global targets for renewable energy use mean that we will rely increasingly on this source of power. Increased reliance on this method of power generation will result in an increased exposure of society to the effect of fires in these facilities. Research is therefore needed to better understand the fire behaviour of the critical components in the nacelle and the contribution of the environmental conditions to the fire growth inside of the nacelle for both suppression and detection requirements. There is also potential for improving fire safety inside of the nacelle by means of taking passive measures [44] - either in the design or construction of the turbine as well as through the management of the facility.

The fire problem in wind turbines is indeed a cause for concern to all stakeholders. First, fire events can cast a shadow on the green credentials of the technology. A second, given the current and projected increases in the use of these facilities and reliance on them, a proactive approach to solving the problem has the potential to significantly reduce the economic costs and threats to society.

\section{REFERENCES}

[1] European Wind Energy Association (EWEA), Wind energy and research, 2009. [Online]. Available: http://www.ewea.org/ [Accessed 2013].

[2] Climate Commission, "The Critical Decade: Generating a renewable Australia," South Australia, Canberra, 2012.

[3] South Australian Advisory Functions, "South Australian Wind Study Report.," Australian Energy Market Operator (AEMO), ABN 94072010 327, 2012.

[4] REPower Australia, "Wind farm Developments in South Australia: Select Committee," 2012. [Online]. Available:

http://www.repower.com.au/fileadmin/user_upload_AU/Submissions/SA_Select_Committee_Inqu iry_Final.pdf. [Accessed 2013].

[5] AEMO, "Nem-Wide Historical Information Report," Australian Energy Market Operator (AEMO), ABN 94072010327.

[6] Global Wind Energy Council (GWEC), "Global Wind Statistics 2012," GWEC, 11.02.2013, Brussels, 2012.

[7] The European Wind Energy Association, "Wind in Power, 2012 European Statustics," 2013. [Online]. Available at http://www.ewea.org/fileadmin/files/library/publications/statistics/Wind_in_power_annual_statisti cs_2012.pdf. [Accessed 2013].

[8] Caithness Windfarm Information Forum, "Summary of Wind Turbine Accident data to 31 December 2012," 2013.

[9] Karl C. Hertenberger et. al, "New Challenges for Wind Energy," 2009. [Online]. Available: http://www.imia.com/downloads/imia_papers/WGP62_2009.pdf. [Accessed 2013].

[10] Confederation of Fire Protection Associations in Europe (CFPA E), Wind Turbines Fire Protection Guideline, No 22:2010 F, 2010. 
[11] Eric Rosenbloom, "A Problem with Wind Power," 05 September 2006. [Online]. Available: http://www.aweo.org/problemwithwind.html. [Accessed 2013].

[12] M. Ragheb, "Safety of Wind Systems," 26 February 2011. [Online]. Available: http://www.windfarmaction.files.wordpress.com/2011/10/safety-of-wind-systems.pdf. [Accessed 2013].

[13] Tory Aardvark, Britain 3421 Wind Turbines Installed, 1500 Accidents In 5 Years, http://toryaardvark.com [Accessed 2013]

[14] E. Malnick and R. Mendick, "The Telegraph: 1,500 accidents and incidents on UK wind farms," 11 December 2011. [Online]. Available: http://www.telegraph.co.uk/news/uknews/8948363/1500accidents-and-incidents-on-UK-wind-farms.html.

[15] D. Ledebvr, Interviewee, Private communication on email about Wind turbine Fires. 2013.

[16] Global Wind Energy Council (GWEC), "Wind in numbers," [Online]. Available: http://www.gwec.net/global-figures/wind-in-numbers/.

[17] BBC News, "Wind turbine fire at Ardrossan wind farm," 8 December 2011. [Online]. Available: http://www.bbc.co.uk/news/uk-16115139. [Accessed 2013].

[18] The Guardian, "Wind power: what really happened when the Ayrshire turbine caught fire?," 28 February 2012. [Online]. Available: http://www.guardian.co.uk/environment/2012/feb/28/windpower-ayrshire-turbine-caught-fire. [Accessed 2013].

[19] S. Bakewell, "Vestas Wind Turbine Catches Fire in Germany, No Injuries," 30 March 2012. [Online]. Available: http://www.businessweek.com/news/2012-03-30/vestas-says-turbine-catchesfire-at-gross-eilstorf-wind-farm.

[20] K. Williamson, "Vestas identifies cause for V112 wind turbine fire," 30 April 2012. [Online]. Available: http://www.renewableenergyfocus.com/view/25458/vestas-identifies-cause-for-v112wind-turbine-fire/.

[21] "Windrad in Flammen," 31 March 2012. [Online]. Available: http://www.kreiszeitung.de/lokales/landkreis_sfa/walsrode/windrad-flammen-2260359.html.

[22] European Platform Against Windfarms, "Wind turbine on fire at the Groß Eilstorf wind farm," [Online]. Available: http://epaw.org/photos/WKA_ausgebrannt_5.jpg. [Accessed 2013].

[23] "Wind Power and Wind Farms in Australia," [Online]. Available: http://ramblingsdc.net/Australia/WindPower.html. [Accessed 2013].

[24] "Wind Action," 2006. [Online]. Available: http://www.windaction.org/news/1607. [Accessed 2013].

[25] ABC news, 2010. [Online]. Available: http://www.abc.net.au/news/2010-02-18/cfs-tackles-lakebonney-blaze/335648. [Accessed 2013].

[26] ABC news, 2006. [Online]. Available: http://www.abc.net.au/news/2006-01-23/experts-try-todetermine-wind-farmblaze-cause/783782 . [Accessed 2013].

[27] "Express-IT," [Online]. Available: http://host2.newworldhosting.co.uk/ expressi/casestudies/nissan-nmuk-windfarm.. [Accessed 0102 2013].

[28] BBC News, "Blazing turbine falls into field," 23 December 2005. [Online]. Available: http://news.bbc.co.uk/2/hi/uk_news/england/wear/4556640.stm. [Accessed 2013].

[29] The Energy Workshop, "Nissan Wind Turbines," [Online]. Available: http://www.theenergyworkshop.co.uk/case-studies.asp. [Accessed 2013].

[30] The Northern Echo, "Car plant windfarm fire forces motorists off A19," 24 December 2005. [Online].

Available:http://www.thenorthernecho.co.uk/archive/2005/12/24/The+North+East+Archive/71532 99.Car_plant_. [Accessed 2013]. 
[31] BBC News, "Human error caused turbine blaze," 1 March 2006. [Online]. Available: http://news.bbc.co.uk/2/hi/uk_news/england/wear/4759926.stm. [Accessed 2013].

[32] Morchat, Richard M., "Technical Memorandum 93/214: The Effects of Zinc Borate Addition on The Flammability Characteristics of Polyester, Vinyl Ester and Epoxy Glass Reinforced Plastic," October 1993. [Online]. Available: www.dtic.mil/dtic/tr/fulltext/u2/a273164.pdf. [Accessed 2013].

[33] J.W. Gilman et. al, "Flammability Studies of Polymer Layered Silicate Nanocomposites," 1999. [Online]. Available: http://fire.nist.gov/bfrlpubs/fire99/PDF/f99164.pdf. [Accessed 2013].

[34] Robert Errichello and Jane Muller, Geartech, "Oil Cleanliness in Wind Turbine Gearboxes," 2002. [Online]. Available: http://www.cjc.dk/fileadmin/user_upload/pdf/News_Press/Press_Info/Oil-. [Accessed 2013].

[35] VdS Verlag, "Wind turbines - Fire protection guideline," German Insurance Association (Gesamtverband der Deutschen Versicherungswirtschaft e.V. - GDV, VdS 3523en: 2008-07 (01).

[36] D. Lesinski, "Synthetics to Protect the Wind Turbine and the Environment. Fire prevention and biodegradability are important factors to consider in selecting gearbox lubricants," 2013.

[37] International Renewable Energy Agency (IRENA), "Wind Power," Renewable Energy Technologies: Cost Analysis Series, vol. Power Sector, no. 5/5, June 2012.

[38] L. Fingersh, M. Hand and A. Laxson, "Wind Turbine Design Cost and Scaling Model," National Renewable Energy Laboratory, 2006.

[39] Avionex/USA Corporation, "Main Components of a Wind Turbine".

[40] B. B. N. Kragelund, "Insurance of Wind Turbines - Update," 2002.

[41] N. Smith and E. de Vries, "Wind and fire - Reducing the risk of fire damage in wind turbines," Renewable energy world, no. September-October, pp. 1-4, 2004.

[42] Brian McNiff, McNiff Light Industry Harborside, "Wind Turbine Lightning Protection Project 1999_2001," National Renewable Energy Laboratory (NREL), Maine, 2001.

[43] B. Glushakow, "Effective Lightning Protection For Wind Turbine Generators," 2007. [Online]. Available: http://www.aseanenergy.info/abstract/31029163.pdf. [Accessed 2013].

[44] U. Solomon, Passive Fire Protection in Wind Turbines for Sustainable Energy, Edinburgh: Master Thesis, University of Edinburgh, 2013.

[45] J.L. Bryan, "Fire Supression and Detection Systems," Glencoe Pres,, 1974.

[46] British Standard, "BS 5839-1:2002 + A2:2008, Fire detection and fire alarm systems for buildings - Part 1: Code of practice for system design, installation, commissioning and maintenance".

[47] "CIBSE Guide E, Fire safety engineering, The Chartered Institution of Building Services Engineers," London, 2010.

[48] J. Rönnblom, "Fire detection in engine compartments of buses - A pilot study," SP Technical Research Institute of Sweden, Luleå University of Technology, Borås, 2011.

[49] R. Dudley, "Automatic Fire Detection and Alarm Systems - An introductory guide to components and systems," BRE, 2010.

[50] Torben Vad, AREPA - Private communication, 2012.

[51] Edlinger Sven, Rotarex - Private communication, 2012. 